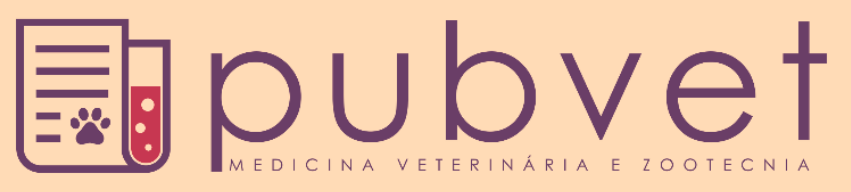

https://doi.org/10.31533/pubvet.v14n8a624.1-9

\title{
Detecção de anticorpos anti-Neospora caninum em bovinos leiteiros na microrregião de Patos de Minas, Minas Gerais
}

\author{
Luis Fernando Faria Coury ${ }^{\circ}$, Brendhal Almeida Silva ${ }^{1}$, Maria Paula Lima Reis ${ }^{1}{ }^{\ominus}$, Andresa \\ dos Santos $\operatorname{Veras}^{2}{ }^{\circ}$, Nadia Grandi Bombonato ${ }^{\circ}{ }^{\circ}$, Mariana Assunção de Souza ${ }^{3}$, Renata Lima \\ de Miranda $^{4} \bullet$, Jacqueline Ribeiro de Castro ${ }^{*} \bullet$ \\ ${ }^{1}$ Graduados em Medicina Veterinária, Centro Universitário de Patos de Minas - UNIPAM - MG, Brasil. \\ ${ }^{2}$ Graduanda em Medicina Veterinária, Faculdade Presidente Antônio Carlos - UNIPAC-MG, Brasil. \\ ${ }^{3}$ Docentes em Medicina Veterinária, Centro Universitário de Patos de Minas - UNIPAM - MG, Brasil. \\ ${ }^{4}$ Médica veterinária, Dra. em Parasitologia no Programa de pós graduação em imunologia e parasitologia aplicada - PIPPA, Universidade \\ Federal de Uberlândia-UFU, MG, Brasil. \\ ${ }^{5}$ Docente em Medicina Veterinária, Centro Universitário do Triângulo - UNITRI - MG, Brasil. \\ *Autor para correspondência, E-mail: jack_ufu@yahoo.com.br
}

\begin{abstract}
Resumo. A neosporose é considerada uma das principais doenças causadoras de aborto, gerando falhas reprodutivas no rebanho bovino. O presente estudo objetivou determinar a presença de anticorpos anti-Neospora caninum em bovinos de rebanhos leiteiros oriundos da microrregião de Patos de Minas, Minas Gerais, bem como, determinar os fatores de risco. Foram coletadas 110 amostras de soro sanguíneo, provenientes de 10 propriedades rurais distintas, sendo amostrados 11 bovinos/propriedade com diagnóstico fundamentado na sorologia por Enzyme Linked Immunosorbent Assay (ELISA). A análise estatística empregada foi descritiva, por meio de frequências absoluta e relativa, utilizando-se um teste não paramétrico Odds Ratio para duas amostras independentes para determinação de fatores de risco, considerando um nível de significância de 5\%, com seleção de possíveis fatores de risco pela aplicação de um questionário epidemiológico. Determinou-se uma ocorrência de 28,2\% (31/110). Vacas avaliadas que exibiram histórico de aborto apresentaram 12,7 vezes mais chances de serem soro reagentes para Neospora caninum $(\mathrm{P}<0,0001)$. Feto abortado não observado $(\mathrm{P}=0,0028)$ e bovinos mestiços $(\mathrm{P}=0,038)$ também foram considerados fatores de risco para a doença. Por se tratar de uma doença reprodutiva impactante na bovinocultura brasileira, com relevante ocorrência detectada $(28,18 \%)$ na microrregião de Patos de Minas, atenta-se para a necessidade de realização de levantamentos epidemiológicos que visem identificar animais soro reagentes e possíveis fatores de risco, para se estabelecer medidas de profilaxia e controle da neosporose.
\end{abstract}

Palavras chave: bovinocultura, doenças reprodutivas, neosporose

\section{Detection of anti-Neospora caninum antibodies in dairy cattle in the microregion of Patos de Minas, Minas Gerais}

\begin{abstract}
Neosporosis is considered one of the main diseases causing abortion, generating reproductive failures in the cattle herd. Present study aimed to determine the presence of antiNeospora caninum antibodies in cattle from dairy herds from the Patos de Minas microregion, Minas Gerais (MG), as well as to determine risk factors. A total of 110 blood serum samples were collected from 10 distinct rural properties, and 11 cattle/property with diagnosis based on serology by Enzyme-Linked Immunosorbent Assay (ELISA) were sampled. The statistical analysis used was descriptive, using absolute and relative frequencies, using a nonparametric Odds Ratio test for two independent samples to determine risk factors, considering a significance level of $5 \%$, with selection of possible risk factors by employment an
\end{abstract}


epidemiological questionnaire. Occurrence of $28.18 \%$ (31/110) was determined. Evaluated cows that exhibited a history of abortion were 12.66 times more likely to be serum reagents for Neospora caninum $(\mathrm{p}<0.0001)$. Unobserved aborted fetus $(\mathrm{P}=0.0028)$ and crossbred cattle $(\mathrm{P}$ $=0.038$ ) were also considered risk factors for the disease. Due to treat of a reproductive disease that has an impact on Brazilian cattle, with a relevant occurrence detected (28.2\%) in the microregion of Patos de Minas, MG, attention is made to the need for epidemiological surveys aimed at identifying sero-reactive animals and possible risk factors, in order to establish measures of prophylaxis and control of neosporosis.

Keywords: bovine culture, reproductive diseases, neosporosis

\section{Detección de anticuerpos anti-Neospora caninum en ganado lechero en la microrregión de Patos de Minas, Minas Gerais}

Resumen. La neosporosis es considerada una de las principales enfermedades que causan el aborto, generando fallas reproductivas en el rebaño de ganado bovino. El presente estudio tenía como objetivo determinar la presencia de anticuerpos anti-Neospora caninum en bovinos de rebaños lecheros oriundos de la microrregión patos de Minas, Minas Gerais, así como determinar los factores de riesgo. Se recogieron un total de 110 muestras de suero sanguíneo de 10 propiedades rurales distintas, y se muestrearon 11 bovinos/propiedades con diagnóstico basado en serología por Enzyme Linked Immunosorbent Assay (ELISA). El análisis estadístico utilizado fue descriptivo, utilizando frecuencias absolutas y relativas, utilizando una prueba de relación de probabilidades no paramétrica para dos muestras independientes para determinar los factores de riesgo, teniendo en cuenta un nivel de significancia del 5\%, con la selección de posibles factores de riesgo mediante la aplicación de un cuestionario epidemiológico. Se determinó una casuística del 28,2\% (31/110). Las vacas evaluadas que mostraban antecedentes de aborto tenían 12,7 veces más probabilidades de ser serorreactivos para Neospora caninum $(\mathrm{P}<0.0001)$. El feto abortado no observado $(\mathrm{p}-0,0028)$ y el ganado cruzado $(\mathrm{P}=0,038)$ también se consideraron factores de riesgo para la enfermedad. Porque es una enfermedad reproductiva que tiene un impacto en el ganado bovino brasileño, con una casuística relevante detectada $(28,18 \%)$ en la micro región de Patos de Minas, se presta atención a la necesidad de realizar estudios epidemiológicos destinados a identificar animales seroreactivos y posibles factores de riesgo, con el fin de establecer medidas de profilaxis y control de la neosporosis.

Palabras clave: ganadería, enfermedades reproductivas, neosporosis

\section{Introdução}

Na bovinocultura leiteira mundial a neosporose é considerada uma das principais doenças causadoras de aborto, gerando falhas produtivas e reprodutivas no rebanho (Innes et al., 2002). Segundo Mendes et al. (2009) e Vogel et al. (2006)é uma parasitose ocorrente no estado de Minas Gerais, como apontam estudos realizados no município de Uberaba (Guedes et al., 2008; Orlando et al., 2013; Varandas et al., 2001), no sul do estado, os quais relataram a distribuição da doença nas respectivas regiões, ocasionando perdas econômicas relevantes.

A Neosporose é uma parasitose causada pelo agente Neospora caninum (N. caninum). Trata-se de um protozoário intracelular obrigatório, que acomete hospedeiros intermediários (bovinos, ovinos, caprinos, equinos, felinos, cervídeos e bubalinos) e definitivos, representados pelos canídeos, com destaque para o cão doméstico, no ambiente rural (Megid et al., 2016).

Os hospedeiros intermediários, por sua vez, se infectam por meio da transmissão horizontal, pela ingestão dos oocistos esporulados pelos canídeos, via fômites, alimento contaminado, restos fetais ou ingestão de cistos teciduais (Snak \& Osaki, 2019) ou pela transmissão vertical (D. S. Santos et al., 2011). Margarido et al. (2008) afirmam em seu estudo que, além dos taquizoítos atingirem o feto, podem ocasionar necrose do placentoma, e eventualmente, pode atingir a glândula mamária, e ser eliminado pelo leite. Hein et al. (2012) sugerem que os animais uma vez infectados, podem manter o parasita no 
rebanho durante gerações, por meio da transmissão vertical, não apresentando manifestações clínicas aparentes e se mantendo como portadores disseminadores do patógeno.

As manifestações clínicas comumente observadas nos bovinos são queda de rendimento da produção leiteira (média de 4\% de redução, conforme relatado por Sousa (2004), aborto, morte embrionária, mumificação fetal, repetição de cio, fetos autolisados, natimortos, nascimento de animais vivos clinicamente normais que posteriormente morrem e, nascimento de bezerros apresentando encefalite, paralisias, ataxias motoras, má formações, pneumonite e miocardite (Cerqueira-Cézar et al., 2017; Sousa, 2004). O aborto é descrito na literatura (Andreotti, 2001; Cerqueira-Cézar et al., 2017; Sousa, 2004) com a principal manifestação reprodutiva, sendo mais ocorrente em vacas primíparas. Devido ao polimorfismo clínico apresentado na neosporose, doenças como brucelose, diarreia viral bovina, rinotraqueíte infecciosa bovina e leptospirose deverão fazer parte da diferenciação diagnóstica (Sousa, 2004).

O diagnóstico da neosporose bovina fundamenta-se em informações clínicas epidemiológicas sendo confirmado por exames laboratoriais, os quais se baseiam na detecção do agente etiológico ou na presença de anticorpos específicos contra o agente. Dentre os exames empregados estão a imunofluorescência indireta (RIFI), o ensaio de imuno absorção enzimática (ELISA) e o teste direto de anti-globulina (TAD) (Cardoso et al., 2008; D. P. G. Melo et al., 2006; Parra et al., 2008; Porto et al., 2018). As amostras de eleição na coleta são placenta, líquidos fetais, cérebro, coração e fígado e para animais adultos, utiliza-se a pesquisa de anticorpos específicos do sangue, leite, colostro, fluídos vaginais e saliva (Cadore et al., 2009; Parra et al., 2008; S. P. Silva et al., 2013).

Devido a neosporose na espécie bovina apresentar manifestações clínicas inespecíficas e perdas produtivas significativas, torna-se desafiador e fundamental a identificação de animais soro reagentes em levantamentos epidemiológicos, a fim de se evitar e controlar a doença.

Dessa forma, objetivou-se determinar a presença de anticorpos anti-Neospora caninum em bovinos de rebanhos leiteiros oriundos da microrregião de Patos de Minas, Minas Gerais (MG), bem como, determinar os de fatores de risco nas propriedades avaliadas.

\section{Material e métodos}

Este estudo foi conduzido conforme os princípios éticos de experimentação animal e mediante a submissão e aprovação do Comitê de Ética no Uso de Animais (CEUA) do Centro Universitário de Patos de Minas (UNIPAM), sendo aprovado com o número do protocolo 04/17, após prévia autorização dos proprietários.

\section{Local do estudo}

O Alto Paranaíba é uma das dez regiões de planejamento do estado de Minas Gerais, sendo constituída por 36 municípios. A mesorregião Triângulo Mineiro-Alto Paranaíba lidera a produção de leite no Brasil sendo considerada uma bacia leiteira, com uma produção estimada de 1569 milhões de litros de leite/ano (Siqueira \& Zoccal, 2012).

A Região do Alto Paranaíba (Figura 1) é composta por três microrregiões, que compreendem Patos de Minas, Patrocínio e Araxá. Nesse estudo foram avaliados os animais presentes na microrregião de Patos de Minas, que compreende em si dez municípios, sendo eles: Arapuá, Carmo do Paranaíba, Guimarânia, Lagoa Formosa, Matutina, Patos de Minas, Rio Paranaíba, Santa Rosa da Serra, São Gotardo e Tiros.

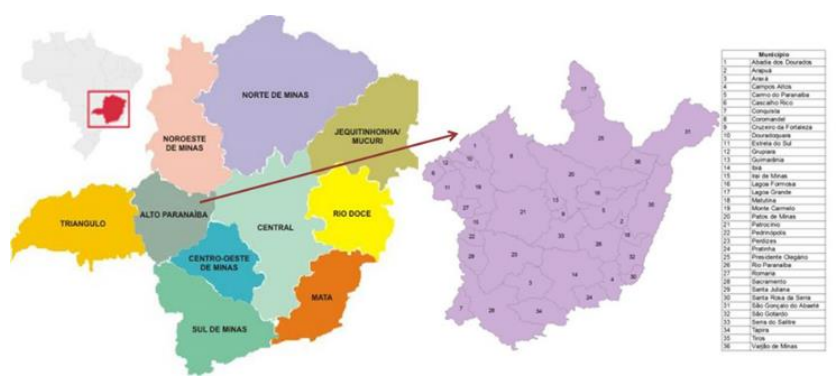

Figura 1. Localização da região do Alto Paranaíba, formada pelas microrregiões de Patos de Minas, Patrocínio e Araxá, no mapa de Minas Gerais. Fonte: Wikipedia (2020). 


\section{Delineamento do estudo e cálculo amostral}

Foi realizado um estudo epidemiológico observacional transversal prospectivo, no período de abril a dezembro de 2017, na microrregião de Patos de Minas, MG.

Para o dimensionamento amostral considerou-se uma prevalência esperada de $29 \%$ de anticorpos contra $N$. caninum, a qual foi encontrada em um estudo prévio (Ragozo et al., 2003) em rebanhos de bovinos pertencentes ao estado de Minas Gerais, Brasil. Utilizou-se um intervalo de confiança de $95 \%$ e erro estimado de 0,05 , estimando uma população de vacas leiteiras e resultando numa amostra de 317 vacas, como descrito no projeto por Thrusfield (2004) para estabelecer um estudo epidemiológico na região do Alto Paranaíba, a qual composta por três microrregiões (microrregião de Patos de Minas, Araxá e Patrocínio), resultando cerca de 106 animais por microrregião. O dimensionamento amostral foi executado no software estatístico SigmaStat ${ }^{\circledR}$ (Windows, versão 3.5.1, Chicago, IL, USA).

A microrregião de Patos de Minas é constituída por dez municípios (Figura 1), sendo amostrados 11 bovinos/propriedade, uma fazenda de cada município na microrregião de Patos de Minas, MG, perfazendo uma amostra de 110 animais.

A seleção das propriedades ocorreu por sorteio probabilístico blindado nos municípios que pertenciam à microrregião de Patos de Minas, conforme um estudo de georreferenciamento (Dittrich et al., 2008) que analisaram a distribuição espacial da produção de leite e quantidade de das vacas ordenhadas por microrregiões, no estado de MG, para que a amostra fosse representativa da microrregião de Patos de Minas.

\section{Caracterização da população e critérios de seleção}

As coletas foram feitas exclusivamente em bovinos leiteiros da microrregião de Patos de Minas, MG, em propriedades previamente selecionadas baseado no cadastro no Instituto Mineiro de Agropecuária (IMA, 2017). Foram inclusas fêmeas adultas da espécie bovina, com idade maior ou igual a 24 meses, destinadas à produção leiteira, independente do padrão racial, em diferentes fases e números de lactações, independentemente do tipo de ordenha, do manejo nutricional e sanitário, criadas sob regime intensivo, semi-intensivo ou extensivo.

Propriedades que não possuíam registros dos animais, quanto aos fatores de risco estudados como histórico reprodutivo, identificação dos animais e desautorização do responsável durante o procedimento de colheita foi retirada do estudo e substituída, em busca da manutenção do n amostral calculado.

\section{Questionário epidemiológico}

Um inquérito epidemiológico foi realizado com a aplicação de uma ficha cadastral e um questionário, a fim de se avaliar os fatores de risco inerentes à ocorrência de animais soro reagentes.

Foram investigados aspectos relacionados à localização da propriedade, idade, raça, histórico produtivo (tipo de ordenha e queda na produção leiteira), reprodutivo (presença de aborto: sim, não, raramente; época do aborto: terço inicial, médio ou final da gestação; aspecto do feto abortado: normal ou necrosado; presença de prolapso uterino, retenção de placenta e descarga vaginal), esquema vacinal e de vermifugação do animal, manejo higiênico sanitário (assistência veterinária, estado nutricional, presença de instalações alagadiças, manuseio de fetos e destino das vacas que abortaram), ambiente, presença coabitantes, presença de animais silvestres e ocorrência de casos de neosporose.

\section{Coleta e processamento do material}

Para a realização do exame sorológico foram colhidos $10 \mathrm{~mL}$ de sangue, por meio da venopunção da veia coccígea, com seringas de $10 \mathrm{~mL}$ e agulhas $25 \times 8$ estéreis, após antissepsia com álcool utilizandose tubos a vácuo, devidamente identificados, sob contenção física dos animais em estação no brete. As amostras foram acondicionadas em tubos sem anticoagulantes para a extração do soro, mantidas cuidadosamente refrigeradas imediatamente após a colheita, em caixa isotérmica com gelo reciclável e encaminhadas ao laboratório de Patologia Clínica do Centro Clínico Veterinário, UNIPAM, centrifugadas por cinco minutos a $3000 \mathrm{rpm}$, aliquotadas em tubos de polietileno de fundo cônico, e armazenadas a $-20^{\circ} \mathrm{C}$ até o processamento no laboratório de Bioquímica, UNIPAM. 
A determinação de anticorpos contra $N$. caninum foi realizada utilizando um kit comercial (Neospora X2 Ab Test, IDEXX, sensibilidade 100\%, especificidade 99,2\%), pelo método Enzyme-Linked Immunosorbent Assay (ELISA) previamente validado para o uso em bovinos (Dittrich et al., 2008) que utiliza anticorpos específicos para $N$. caninum, sendo as amostras processadas em duplicatas.

\section{Análise estatística}

Para cálculo da frequência foi dividido o número de animais soro reagentes pelo número de animais amostrados, utilizou-se análise estatística descritiva por meio de frequências absoluta e relativa. Para análise e determinação dos fatores de risco utilizou-se um teste não paramétrico Odds Ratio, para duas amostras independentes, considerando um nível de significância de 5\%. O programa utilizado para a análise estatística foi o Graphpad versão 5.0 para Windows (San Diego, California, USA).

\section{Resultados e discussão}

Ao se analisar as 110 amostras de soro sanguíneo, 31 apresentaram-se reagentes, determinando assim, uma ocorrência de $28,18 \%$. Esse resultado corrobora com levantamentos soroepidemiológicos de vacas leiteiras no Brasil, em que, a média de prevalência encontrada foi de 30\% (Chiebao, 2010; Melo et al., 2006; Mineo et al., 2010; Moura et al., 2012; Orlando et al., 2013; Oshiro et al., 2007; Piagentini, 2003; Santos et al., 2009; Silva et al., 2008; Sousa et al., 2012; Teixeira et al., 2010).

Vacas avaliadas que exibiram histórico de aborto apresentaram 12,66 vezes mais chances de serem soro reagentes para Neospora caninum (Tabela 1).

Tal fato pode ser explicado por ser considerada uma das principais doenças de cunho reprodutivo na bovinocultura leiteira mundial causadora de aborto, gerando falhas reprodutivas no rebanho (Innes et al., 2002; Margarido et al., 2008; Megid et al., 2016). Sousa (2004) descreveu a enfermidade causada pelo $N$. caninum causadora de aborto em bovinos em momentos não fisiológicos e perdas, como a mortalidade de embriões, a perda produtiva de leite, o nascimento de bezerros com anormalidades congênitas e perdas zootécnicas no desenvolvimento dos nascidos. O aborto é descrito na literatura (Andreotti, 2001) como sendo mais frequente na primeira gestação quando comparado as seguintes, entretanto, outros fatores também podem se tornar relevantes, como a presença de outras doenças, o estresse e o tempo da infecção instalada.

Os animais soro reagentes que apresentaram aborto em algum estágio de sua vida produtiva (83\%) apresentaram o mesmo de forma distribuída, sendo no primeiro terço $7,7 \%$, na metade da gestação $23,1 \%$ e no terço final 65\%. Estes dados quando comparados com Dubey et al. (2002), Guy et al. (2001) e Williams et al. (2000) sugerem que talvez, os animais acometidos podem apresentar outras doenças reprodutivas. Uma vez que no último trimestre de gestação o feto é mais imunocompetente e o feto pode nascer normalmente, porém com a infecção adquirida congênita.

Os animais reagentes que não apresentaram aborto $(17,0 \%)$ podem, entretanto, ter tido em algum momento de sua vida contato com o agente, ou até mesmo serem infectados congenitamente, uma vez que, vacas com exposição prévia ao agente são menos propensas a abortar que vacas primoinfectadas (McAllister et al., 1998). Entretanto, caso estes animais sejam primoinfectados, os mesmos podem ter tido uma perda embrionária no início da gestação não diagnosticada.

As variáveis assistência veterinária, retenção de placenta, presença de prolapso, destino do feto abortado, tipo de instalação e escore de condição corporal não foram significantes $(\mathrm{P}>0,05)$ como fatores de risco. As variáveis presença de cães e animais silvestres, vermifugação e vacinação não foram avaliadas, pois todos os animais das propriedades avaliadas apresentavam, independentes se eram reagentes.

Silva et al. (2008) citam que o sistema de criação interfere nos achados sorológicos, sendo que em criações extensivas $(36,7 \%)$ possuem maiores índices de animais positivos do que criações intensivas $(11,1 \%)$, entretanto, Melo (2001) relataram não haver diferença significativa, em Minas Gerais. No presente estudo, em que foram analisados animais provenientes de dois tipos de criação, semi-intensivo (animais em piquetes) e intensivo (animais em copost barn), identificou-se $21 \%$ de animais positivos dentre os mantidos em compost barn e 31,2\% de animais mantidos em sistemas de piquete, sugerindo assim, maior risco de infecção. 
Tabela 1. Distribuição das fêmeas bovinas reagentes conforme os fatores de risco avaliados, na microrregião de Patos de Minas, MG, 2017.

\begin{tabular}{|c|c|c|c|c|c|c|}
\hline \multirow[t]{2}{*}{ Variáveis } & \multicolumn{3}{|c|}{ Fêmeas Bovinas } & \multirow{2}{*}{$O r^{*}$} & \multirow{2}{*}{ Ic $95 \%$} & \multirow{2}{*}{$\mathrm{P}$} \\
\hline & Total & Regentes & Frequência (\%) & & & \\
\hline \multicolumn{7}{|l|}{$\overline{\text { Idade (anos) }}$} \\
\hline Adultas jovens (3-5) & 37 & 10 & 27,02 & \multirow{3}{*}{$1,13^{*}$} & \multirow{3}{*}{$0,45-2,81$} & \multirow{3}{*}{0,8178} \\
\hline Adultas maduras (6-8) & 59 & 17 & 28,81 & & & \\
\hline Velhas $(9-12)$ & 14 & 4 & 28,57 & & & \\
\hline \multicolumn{7}{|l|}{ Aborto } \\
\hline Sim & 31 & 26 & 83,87 & \multirow{2}{*}{12,66} & \multirow{2}{*}{$4,3-37$} & \multirow{2}{*}{$\mathrm{P}<0,0001$} \\
\hline Não & 79 & 23 & 29,11 & & & \\
\hline \multicolumn{7}{|l|}{ Aspecto do feto } \\
\hline Normal & 19 & 7 & 36,84 & \multirow{3}{*}{$0,17 *$} & \multirow{3}{*}{$0,04-0,77$} & \multirow{3}{*}{0,0028} \\
\hline Necrosado & 13 & 6 & 46,15 & & & \\
\hline Não observado & 17 & 13 & 76,47 & & & \\
\hline \multicolumn{7}{|l|}{ Raça } \\
\hline Mestiços*** & 33 & 14 & 82,35 & \multirow{2}{*}{$2,60 *$} & \multirow{2}{*}{$1,08-6,24$} & \multirow{2}{*}{0,0383} \\
\hline Holandês & 77 & 17 & 22,07 & & & \\
\hline \multicolumn{7}{|l|}{ Retenção de placenta } \\
\hline Sim & 29 & 6 & 20,68 & \multirow{2}{*}{0.58} & \multirow{2}{*}{$0,21-1,61$} & \multirow{2}{*}{0,3447} \\
\hline Não & 81 & 23 & 28,39 & & & \\
\hline \multicolumn{7}{|l|}{ Assistência veterinária } \\
\hline Presente & 99 & 25 & 25,25 & \multirow{2}{*}{$0,28 * *$} & \multirow{2}{*}{$0,07-1,0$} & (20710 \\
\hline Ausente & 11 & 6 & 54,54 & & & $0,0 / 10$ \\
\hline Instalações & & & & & & \\
\hline Compost barn & 33 & 7 & 21,21 & 0.50 & 022155 & 2505 \\
\hline Sem compost barn & 77 & 24 & 31,16 & 0,59 & $0,22-1,53$ & 0,3585 \\
\hline Prolapso & & & & & & \\
\hline Sim & 4 & 1 & 25 & 094 & 00 e 44 & 10000 \\
\hline Não & 106 & 3 & 2,83 & 0,84 & $0,08-\varnothing, 44$ & 1,0000 \\
\hline ECC & & & & & & \\
\hline $2,25-2,75$ & 58 & 14 & 24,13 & & & \\
\hline $3-3,5$ & 49 & 16 & 32,65 & 0,63 & $0,05-7,56$ & 1,0000 \\
\hline $3,75-4$ & 3 & 1 & 33,33 & & & \\
\hline Destino do feto aborta & & & & & & \\
\hline Enterrado & 44 & 10 & 22,72 & & & \\
\hline Sem destino adequado & 44 & 17 & 38,66 & $2,83 * *$ & $0,81-9,81$ & 0,1599 \\
\hline Incinerado & 22 & 4 & 18,18 & & & \\
\hline
\end{tabular}

As propriedades rurais avaliadas conforme a localização na microrregião estudada e a detecção de animais sororreagentes encontram-se detalhadas a seguir (Tabela 2).

Das 11 fazendas analisadas $10(90,9 \%)$ apresentaram pelo menos um animal sororreagente, exceto o município Patos de Minas (MG), o qual não apresentou amostra reagente para Neospora caninum nas vacas leiteiras, entretanto, esse fato não é sugestivo de uma zona livre da doença, uma vez que, diversos fatores de riscos são relevantes para a ocorrência (Cerqueira-Cézar et al., 2017; Snak \& Osaki, 2019) e a amostragem de uma única propriedade da microrregião pode ser considerada um fator de limitação do presente estudo (Silva et al., 2008). A detecção de animais reagentes no presente estudo encontra-se de acordo com Vogel et al. (2006) e Mendes et al. (2009) os quais afirmaram que a neosporose é uma parasitose ocorrente no estado de Minas Gerais (MG), em pesquisas realizadas por Varandas et al. (2001) no município de Uberaba e Guedes et al. (2008) no sul do estado, que relataram a distribuição 
da doença na região, ocasionando perdas econômicas relevantes. Vale salientar que esse estudo epidemiológico identificou animais que apresentaram anticorpos contra $N$. caninum não sendo sinônimo de animais doentes, assim como destacaram Sartor et al. (2003) em seu estudo e afirmaram que a presença de um anticorpo em determinado hospedeiro não é suficiente para diagnóstico como único agente causador da doença de um rebanho.

Tabela 2. Distribuição de bovinos reagentes a Neospora caninum de acordo com a localização da propriedade na microrregião de Patos de Minas, MG, 2017

\begin{tabular}{lllcc}
\hline Propriedade & Município & $\mathrm{n}$ & Soror reagentes & Ocorrência $(\%)$ \\
\hline A & Guimarânia & 3 & 27,27 \\
B & Rio Parnaíba & 11 & 4 & 36,36 \\
C & Arapuá & 11 & 6 & 54,54 \\
D & São Gotardo & 11 & 3 & 27,27 \\
E & Santa Rosa & 11 & 2 & 18,18 \\
F & Patos de Minas & 11 & 0 & 0 \\
G & Carmo do Parnaíba & 11 & 5 & 45,45 \\
H & Matutina & 11 & 4 & 36,36 \\
I & Tiros & 11 & 2 & 18,18 \\
J & Lagoa Formosa & 11 & 2 & 18,18 \\
\hline
\end{tabular}

\section{Conclusão}

A detecção de anticorpos anti-Neospora caninum foi de 28,18\% (31/110) na microrregião de Patos de Minas, MG. Os fatores de risco identificados foram históricos de aborto, feto abortado não observado e bovinos mestiços (cruzamento de holandês). Por se tratar de uma doença reprodutiva relevante nos bovinos, atenta-se para a necessidade de realização de levantamentos epidemiológicos para a identificação de animais sororreagentes na região estudada, a fim de se controlar e evitar a ocorrência dessa doença.

\section{Referências bibliográficas}

Andreotti, R. (2001). Neosporose: um possível problema reprodutivo para o rebanho bovino. Hora Veterinária, 122, 65-67.

Cadore, G. C., Vogel, F. S. F., Flores, E. F., Sangioni, L. A., \& Camillo, G. (2009). Susceptibility of cell lines and primary cell cultures to Neospora caninum. Ciência Rural, 39(5), 1581-1586. DOI: https://doi.org/10.1590/s0103-84782009005000093

Cardoso, J. M. S., Funada, M. R., Soares, R. M., \& Gennari, S. M. (2008). Perfil sorológico dos anticorpos colostrais para Neospora caninum em bezerros livres da infecção. Brazilian Journal of Veterinary Research and Animal Science, 45(5), 379-384. DOI: https://doi.org/10.11606/issn.16784456.bjvras.2008.26679

Cerqueira-Cézar, C. K., Calero-Bernal, R., Dubey, J. P., \& Gennari, S. M. (2017). Tudo sobre neosporose no Brasil. Revista Brasileira de Parasitologia Veterinária, 26(3), 253-279. DOI: https://doi.org/10.1590/s1984-29612017045

Chiebao, D. P. (2010). Frequência de anticorpos anti-Neospora caninum, anti-Brucella abortus e antiLesptospira spp. em bovinos do Estado do Pará: estudo de possíveis variáveis para ocorrência de infecção. Universidade de São Paulo. DOI: https://doi.org/10.11606/d.10.2010.tde-10022011-135252

Dittrich, R. L., Machado Júniorr, P. C., Fridlund, N., Richartz, R. R., Ferreira., F. M., Patrício, L. F., \& Pieppe, M. (2008). Determinação e correlação de anticorpos anti-Neospora caninum em bovinos e cães do Paraná, Brasil. Revista Brasileira de Parasitologia Veterinária, 17(1), 191-195.

Dubey, J. P., Barr, B. C., Barta, J. R., Bjerkås, I., Björkman, C., Blagburn, B. L., Bowman, D. D., Buxton, D., Ellis, J. T., \& Gottstein, B. (2002). Redescription of Neospora caninum and its differentiation from related coccidia. International Journal for Parasitology, 32(8), 929-946. DOI: https://doi.org/10.1016/s0020-7519(02)00094-2

Guedes, M. H. P., Guimarães, A. M., Rocha, C. M. B. M., \& Hirsch, C. (2008). Freqüência de anticorpos anti-Neospora caninum em vacas e fetos provenientes de municípios do sul de Minas Gerais. Revista 
Brasileira de Parasitologia Veterinária, 17(4), 189-194. DOI: https://doi.org/10.1590/s198429612008000400004

Guy, C. S., Williams, D. J. L., Kelly, D. F., McGarry, J. W., Guy, F., Björkman, C., Smith, R. F., \& Árvores, A. J. (2001). Neospora caninum em vacas prenhes persistentemente infectadas: a infecção transplacentária espontânea está associada a um aumento agudo do anticorpo materno. O Registro Veterinário, 149(15), 443-449.

Hein, H. E., Machado, G., Miranda, I., Costa, E. F., Pellegrini, D. C. P., Driemeier, D., \& Corbellini, L. G. (2012). Neosporose bovina: avaliação da transmissão vertical e fração atribuível de aborto em uma população de bovinos no Estado do Rio Grande do Sul. Pesquisa Veterinária Brasileira, 32(5), 396-400. DOI: https://doi.org/10.1590/s0100-736x2012000500006

IMA (Instituto Mineiro de Agropecuária). (2017). Disponivel em: http://ima.mg.gov.br/.

Innes, E. A., Andrianarivo, A. G., Björkman, C., Williams, D. J. L., \& Conrad, P. A. (2002). Immune responses to Neospora caninum and prospects for vaccination. Trends in Parasitology, 18(11), 497504. DOI: https://doi.org/10.1016/s1471-4922(02)02372-3

Margarido, R. S.; Lima, D. N.; Monteiro, J. R.; Neves, M. F. (2008). Neosporose. Revista Científica Eletrônica de Medicina Veterinária, VI (11), 1-7.

McAllister, M. M., Dubey, J. P., Lindsay, D. S., Jolley, W. R., Wills, R. A., \& McGuire, A. M. (1998). Rapid communication: Dogs are definitive hosts of Neospora caninum. International Journal for Parasitology, 28(9), 1473-1479.

Megid, J., Ribeiro, M. G., \& Paes, A. C. (2016). Doenças infecciosas em animais de produção e de companhia. Roca.

Melo, C. B. (2001). Neospora caninum: Distribuição de anticorpos em três faixas etárias de rebanhos bovinos de leite em Minas Gerais. Revista Brasileira de Reprodução Animal, 25(9), 250-251.

Melo, D. P. G., Silva, A. C., Ortega Mora, L. M., Bastos, S. A., \& Boaventura, C. M. (2006). Prevalência de anticorpos anti-Neospora caninum em bovinos das microrregiões de Goiânia e Anápolis, Goiás, Brasil. Revista Brasileira de Parasitologia Veterinária, 15(3), 105-109.

Mendes, M. B., Bittar, J. F. F., Pereira, W. A. B., Arduino, G. de G. C., Bittar, E. R., do Carmo Panetto, J. C., \& Santos, J. P. (2009). Determinação da prevalência das principais doenças da reprodução no rebanho bovino da região de Uberaba-MG. Ciência Animal Brasileira, 772-777.

Mineo, T. W. P., Oliveira, C. J. F., Gutierrez, F. R. S., \& Silva, J. S. (2010). Recognition by toll-like receptor 2 induces antigen-presenting cell activation and Th1 programming during infection by Neospora caninum. Immunology and Cell Biology, 88(8), 825-833. DOI: https://doi.org/10.1038/icb.2010.52

Moura, A. B., Osaki, S. C., Zulpo, D. L., Garcia, J. L., \& Teixeira, E. B. (2012). Occurrence of antiNeospora caninum antibodies in beef cattle of microrregion of Guarapuava, Paraná State, Brazil. Arquivos Do Instituto Biológico, 79(3), 419-422. DOI: https://doi.org/10.1590/s180816572012000300014

Orlando, D. R., Costa, R. C., Soares, B. A., Oliveira, N. S. C., Nascimento, L. C., Peconick, A. P., Raymundo, D. L., \& Varaschin, M. S. (2013). Abortos por Neosporacaninum em bovinos do sul de Minas Gerais. Pesquisa Veterinária Brasileira, 33(11), 1332-1338. DOI: https://doi.org/10.1590/s0100-736x2013001100008

Oshiro, L. M., Matos, M. de F. C., Oliveira, J. M., Monteiro, L. A. R. C., \& Andreotti, R. (2007). Prevalence of anti-Neospora caninum antibodies in cattle from the state of Mato Grosso do Sul, Brazil. Revista Brasileira de Parasitologia Veterinária, 16(3), 133-138. DOI: https://doi.org/10.1590/s1984-29612007000300004

Parra, B. C., Parra, B. S., \& Neves, F. N. (2008). Neosporose uma doença que acomete abortos em bovinos. Revista Científica Eletretrônica de Medicina Veterinária, 6(1), 1-5.

Piagentini, M. (2003). Dinâmica da infecção por Neospora caninum em rebanhos leiteiros do município de Avaré/SP. Parasitology Research, 111, 717-721.

Porto, Y. F., Pinto Neto, A., Bernardi, F., Possa, M. G., Mota, M. F., Martinez, A. C., Merlini, L. S., \& Berber, R. C. (2018). Occurrence of brucellosis, leptospirosis and neosporosis in cows with retained placenta in Southwest Paraná, Brazil. Pesquisa Veterinária Brasileira, 38(8), 1537-1542. DOI; 
https://doi.org/10.1590/1678-5150-pvb-5415

Ragozo, A. M. A., Paula, V. S. O., Souza, S. L. P., Bergamaschi, D. P., \& Gennari, S. (2003). Ocorrência de anticorpos anti-Neospora caninum em soros bovinos procedentes de seis estados brasileiros. Revista Brasileira de Parasitologia Veterinária, 12(1), 33-37.

Santos, D. S., Andrade, M. P., Varaschin, M. S., Guimarães, A. M., \& Hirsch, C. (2011). Neospora caninum in bovine fetuses of Minas Gerais, Brazil: genetic characteristics of rDNA. Revista Brasileira de Parasitologia Veterinária, 20(4), 281-288. DOI: https://doi.org/10.1590/s1984-29612011000400005

Santos, R. R. D., Guimares, A. M., Rocha, C. M. B. M., \& Hirsch, C. (2009). Frequência de anticorpos anti-neospora caninum em bezerras e novilhas de rebanhos leiteiros na microrregião de lavras, MG. Ciência Animal Brasileira, 10(1), 271-280.

Sartor, I. F., Hasegawa, M. Y., Canavessi, A. M. O., \& Pinckney, R. D. (2003). Ocorrence of Neospora caninum antibody in dairy cows assayed by ELISA and IFAT from Avaré county, SP. Semina: Ciências Agrárias, 24(1), 3-10. DOI: https://doi.org/10.5433/1679-0359.2003v24n1p3

Silva, M. I. S., Almeida, M. Â. O., Mota, R. A., Pinheiro Júnior, J. W. P., \& Rabelo, S. S. A. (2008). Fatores de riscos associados à infecção por Neospora caninum em matrizes bovinas leiteiras em Pernambuco. Ciência Animal Brasileira, 9(2), 455-461.

Silva, S. P., Mota, R. A., Faria, E. B., Casseb, A. R., Casseb, L., \& Dias, H. L. T. (2013). Comparação das técnicas de ELISA indireto e Imunofluorescência indireta na detecção de anticorpos antiNeospora caninum em búfalas (Bubalus bubalis). Pesquisa Veterinária Brasileira, 33(4), 431-434. DOI: https://doi.org/10.1590/s0100-736x2013000400003

Siqueira, K. B., \& Zoccal, R. (2012). PANORAMA DO LEITE. Boletim Eletrônico Mensal. Embrapa Gado de Leite, 6(73).

Snak, A., \& Osaki, S. C. (2019). Uma revisão sobre três importantes agentes causadores de aborto em bovinos: Neospora caninum, Leptospira sp. e Trypanosoma vivax. Revista de Ciência Veterinária e Saúde Pública, 6(1), 160-195. DOI: https://doi.org/10.4025/revcivet.v6i1.39623

Sousa, L. D. G. (2004). Neosporose. Trabalho de Conclusão do Curso de Medicina Veterinária, Faculdades Integradas - UPIS, Brasília - DF, dez, pg. 35-44.

Sousa, M. E., Wagnner, J. N., Albuquerque, P. P. F., Souza Neto, O. L., Faria, E. B., Pinheiro Júnior, J. W., \& Mota, R. A. (2012). Soroprevalência e fatores de risco associados à infecção por Neospora caninum em bovinos leiteiros no estado de Alagoas. Pesquisa Veterinária Brasileira, 32(10), 1009-1013.

Teixeira, W. C., Uzêda, R. S., Gondim, L. F. P., Silva, M. I. S., Pereira, H. M., Alves, L. C., \& Faustino, M. A. G. (2010). Prevalência de anticorpos anti-Neospora caninum (Apicomplexa: Sarcocystidae) em bovinos leiteiros de propriedades rurais em três microrregiões no estado do Maranhão. Pesquisa Veterinária Brasileira, 30(9), 729-734. DOI: https://doi.org/10.1590/s0100-736x2010000900004

Thrusfield, M. V. (2004). Epidemiologia Veterinária (Vol. 1). Roca, Brasil.

Varandas, N. P., Rached, P. A., Costa, G. H. N., Souza, L. M., Castagnolli, K. C., \& Costa, A. J. (2001). Frequência de anticorpos anti-Neospora caninum e anti-Toxoplasma gondii em cães da região nordeste do Estado de São Paulo: correlação com neuropatias. Semina: Ciências Agrárias, 22(1), 105-111. DOI: https://doi.org/10.5433/1679-0359.2001v22n1p105

Vogel, F. S. F., Arenhart, S., \& Bauermann, F. V. (2006). Anticorpos anti-Neospora caninum em bovinos, ovinos e bubalinos no Estado do Rio Grande do Sul. Ciência Rural, 36(6), 1948-1951. DOI: https://doi.org/10.1590/s0103-84782006000600048

Wikipedia. (2020). https://pt.wikipedia.org/wiki/Lista_de_mesorregi\%C3\%B5es_e_ microrregi\%C3\%B5es_de_Minas_Gerais\#Mesorregi\%C3\%A3o_do_Tri\%C3\%A2ngulo_Mineiro_ e_Alto_Parana\%C3\%ADba

Williams, D. J. L., Guy, C. S., McGarry, J. W., Guy, F., Tasker, L., Smith, R. F., MacEachern, K., Cripps, P. J., Kelly, D. F., \& Trees, A. J. (2000). Neospora caninum-associated abortion in cattle: the time of experimentally-induced parasitaemia during gestation determines foetal survival. Parasitology, 121(4), 347-358. DOI: https://doi.org/10.1017/s0031182099006587

Recebido: 18 de março, 2020.

Aprovado: 15 de abril, 2020

Disponível online: 16 de agosto, 2020.
Licenciamento: Este artigo é publicado na modalidade Acesso Aberto sob a licença Creative Commons Atribuição 4.0 (CC-BY 4.0), a qual permite uso irrestrito, distribuição, reprodução em qualquer meio, desde que o autor e a fonte sejam devidamente creditados. 